
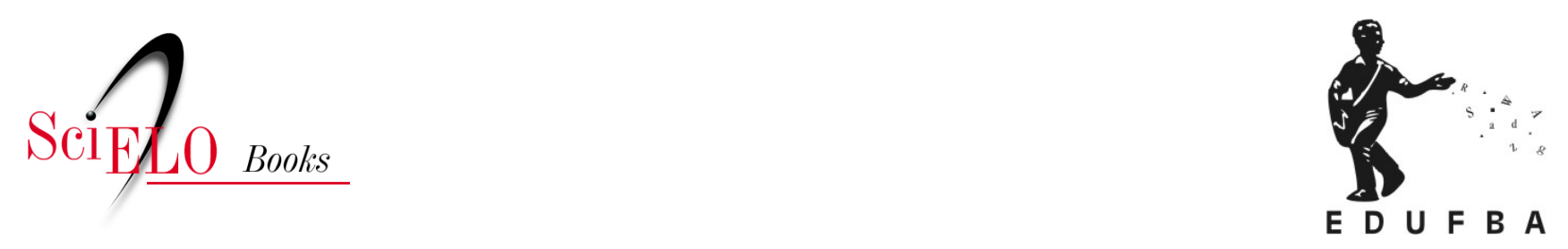

\title{
Tema 2 - Whatsapp e processos educativos Interações no ciberespaço: estudos e pesquisas sobre o Whatsapp na educação no Brasil e Portugal
}

\author{
Ronaldo Nunes Linhares \\ Alexandre Meneses Chagas \\ Elbênia Marla Ramos Silva
}

LINHARES, R.N., CHAGAS, A.M., and SILVA, E.M.R. Interações no ciberespaço: estudos e pesquisas sobre o Whatsapp na educação no Brasil e Portugal. In: PORTO, C., OLIVEIRA, K.E., and CHAGAS, A., comp. Whatsapp e educação: entre mensagens, imagens e sons [online]. Salvador: Ilhéus: EDUFBA; EDITUS, 2017, pp. 87-111. ISBN 978-85-232-2020-4. https://doi.org/10.7476/9788523220204.0006.

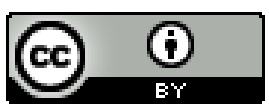

All the contents of this work, except where otherwise noted, is licensed under a Creative Commons Attribution 4.0 International license.

Todo o conteúdo deste trabalho, exceto quando houver ressalva, é publicado sob a licença Creative Commons Atribição $\underline{4.0}$. 


\section{TEMA 2 \\ WHATSAPP E PROCESSOS EDUCATIVOS}




\title{
INTERAÇÓES NO CIBERESPAÇO: ESTUDOS E PESQUISAS SOBRE O WHATSAPP NA EDUCAÇÃO NO BRASIL E PORTUGAL
}

\author{
Ronaldo Nunes Linhares - UNIT \\ Alexandre Meneses Chagas - UNIT \\ Elbênia Marla Ramos Silva - UA
}

\section{Introdução}

O crescente desenvolvimento das tecnologias digitais vem transformando os hábitos e inserindo diferentes formas de comunicar e de fazer comunicaçáo. Vivemos numa era digital em que, quando menos esperamos, somos surpreendidos por um novo objeto e uma nova tecnologia que provoca impactos significativos nos mais diversos âmbitos sociais.

Para Okada (2008), a nova cena sociotécnica de informaçáo e comunicaçáo se caracteriza por uma nova forma de materializaçáo. A autora chama atençáa para as transformaçóes provenientes das mudanças na forma e nos suportes para a produção e circulação de informaçáo que passaram dos mediadores analógicos e atômicos para os bit, códigos digitais universais. Tal qual a escrita, produzida e divulgada em suportes e códigos dialógicos, os novos códigos e formas de registro e publicização criam novas formas de socialização dessa mesma informação. A associação da informática com as telecomunicaçôes possibilita a emergência de uma revolução digital. 
Ao considerar, entre outras coisas, o papel da informação no processo de socialização, subjetivação e humanização; a importância da comunicação e suas formas no ecossistema educativo, formal ou informal; o fortalecimento e ampliação das possibilidades da "Rede" digital como via de socialização na cibersociedade e a transformação da informação em mercadoria numa sociedade de capitalismo globalizado fortaleceram e universalizaram as transformaçóes provocadas pela emergência dos "novos códigos digitais universais", Okada (2008, p. 3), observa que,

digitalizada, a informação se reproduz, circula, modifica e se atualiza em diferentes interfaces. É possível digitalizar sons, imagens, gráficos, textos, enfim uma infinidade de informaçóes. [...] Novos processos criativos podem ser potencializados pelos fluxos sócio-técnicos de ambientes virtuais de aprendizagens que utilizam o digital como suporte.

Para uma sociedade de consumo é fundamental acompanhar a demanda por novos suportes e dispositivos tecnológicos, novos programas, softwares, aplicativos e ambientes de aprendizagem que interligam os sujeitos à informação mediada por meios de comunicação em redes que, do local, se expandem no processo de virtualização para o global. O virtual, entendido como potência, "vir a ser", define a natureza das relaçóes abertas, colaborativas, interativas, hipertextuais e multimidiáticas que, mediadas por suportes e dispositivos sociotécnicos digitais e de comunicaçáo móvel, modificam os processos de aprendizagem a partir de novas formas de comunicaçóes interpessoais, sua vinculação com o consumo de conteúdo, socialização, produção, veiculação e publicação de conteúdo.

Este artigo tem como propósito identificar os estudos sobre as práticas de uso do WhatsApp na educação brasileira e portu- 
guesa. É certo que este tema ainda é novo, mas consideramos as transformaçôes que os dispositivos e plataformas móveis têm proporcionado na sociedade.

\section{M-Learning: redes sociais e aprendizagem via aplica- tivos comunicacionais}

Quando Dewey escreveu o livro Democracia e Educação a sociedade de seu tempo estava passando por uma ruptura de cunho social e tecnológica, com a utilizaçáo das estradas asfaltadas, permitindo longas viagens de grupos maiores de pessoas, a comunicação sem fio que transpassava o atlântico, permitindo uma ampliaçáo da comunicação mundial. Se considerarmos o desenvolvimento das infovias digitais, a colocação de Dewey permanece atual, pois estamos vivenciando uma nova ruptura social e tecnológica, agora com a internet e as tecnologias móveis. Sendo que os ditos "canais para a distribuiçấo de mudanças" hoje fazem parte da nossa vida diária e levamos para todos os lugares (SHARPLES; TAYLOR; VAVOULA, 2007), ou seja, vivemos e vivenciamos "Uma sociedade que é móvel, que é cheia de canais para a distribuição de mudanças ocorrendo em qualquer lugar, deve assegurar que seus membros sejam educados para a iniciativa pessoal e adaptabilidade" (DEWEY, 1936, p. 188) ${ }^{1}$.

É muito comum ao pensar sobre a aprendizagem móvel (m-learning) relacionar apenas ao dispositivo, principalmente o celular, mas devemos deixar claro que o dispositivo é apenas o meio para possibilitar uma mobilidade do aluno durante o seu processo de aprendizagem. Essa mobilidade deve ir além das premissas básicas da comunicação com o professor, o colega e de acesso ao con-

1 "A society which is mobile, which is full of channels for the distribution of a change occurring anywhere, must see to it that its members are educated to personal initiative and adaptability" (DEWEY, 1936, p. 88). 
teúdo, claro que como dito, são premissas básicas para contribuir com a mobilidade do aluno. Mas, qual a situação da utilização por parte dos alunos em relação aos dispositivos móveis?

Com base na pesquisa Tic Domicílio de 2015, o percentual de usuários que utilizam o celular como forma de acessar a internet demonstra o potencial do m-learning, em média 90\% dos entrevistados utilizam o celular para acessar a internet, sendo: 95\% Região Norte; 93\% Região Centro-Oeste; 90\% Regiáo Nordeste; 89\% Sudeste e $85 \%$ Região Sul. Filtrando por faixa etária que compreende a média do aluno de cursos superiores de 16 a 34 anos essa média de acesso aumenta para 95,5\%. Deste público (16 a 34 anos), $49,5 \%$ realizaram atividades ou pesquisas acadêmicas e $44 \%$ estudaram por conta própria, utilizando a internet.

Diante destes dados, podemos observar que ainda temos muitos alunos para motivar no uso dos dispositivos móveis para ampliar sua aprendizagem. Estes dispositivos ampliam as possibilidades de contato do aluno com diversos contextos e narrativas. Numa visão da aprendizagem móvel com base no contexto, Mike Sharples, Taylor e Vavoula (2007) afirmam que a característica da aprendizagem está no processo de conhecer por meio de conversas entre vários contextos, acontecendo entre pessoas e tecnologias interativas.

Há de se concordar que os dispositivos móveis atuais, as pessoas e as conexóes sem fio, são responsáveis por uma transformação nas formas de aprender, no surgimento de novas profissóes, novas linguagens, novas formas de se comercializar produtos e principalmente serviços e estas mudanças aceleradas alteram os contextos continuamente (TRAXLER, 2009). Numa visão comparativa do impacto dos dispositivos digitais móveis no processo de comunicação na atualidade, Aguado, Feijóo e Martinéz (2013) observam que para alcançar uma audiência de 50 milhóes de consumidores, o rádio levou 38 anos, a televisão levou 14, a internet 4 anos para conectar o mesmo número de usuários, o primeiro smartphone levou apenas dois anos para vender 50 milhóes de aparelhos. 
Ainda com base na perspectiva do contexto, Koole (2009) apresenta uma visão holística para a aprendizagem móvel, em que ela é uma convergência das interaçôes dos alunos (ou aprendentes), com seus dispositivos e com a sociedade (outras pessoas). No qual aborda os aspectos do dispositivo, do aluno e do social para uma boa aprendizagem móvel.

Os aspectos dos dispositivos compreendem: 1 - características físicas: como impacta no uso do dispositivo ao se mover; 2 - capacidade de entrada: permite conectar dispositivos para entrada de dados, como teclado etc.; 3 - capacidade de saída: permite a saída de dados, para um projetor etc.; 4 - capacidade de armazenamento: possibilidade de armazenamento do dispositivo para aplicativos e dados a serem utilizados; 5 - velocidade de processamento: é suficiente para atender a necessidade do usuário; 6 - taxa de erros: os usuários podem não ser capazes de executar as tarefas desejadas e podem perder confiança no dispositivo (KOOLE, 2009)

Já os aspectos do usuário são: 1 - conhecimento prévio: afeta positivamente o aluno em compreender novos conceito, em aceitar novos modelos de conteúdos; 2 - memória: o uso de elementos multimídia trabalha diversos estímulos, podendo ajudar os alunos a entender e reter conceitos mais facilmente; 3 - contexto e transferência: utilizar metodologias ativas no auxílio à informação para que os alunos lembrem, compreendam e transfiram conceitos para contextos variados; 4 - descoberta aprendendo: pode estimular o aluno a desenvolver habilidades para "filtrar, escolher e reconhecer" informaçôes relevantes em diferentes situaçôes; 5 - emoçóes e motivaçóes: a disposição de um aluno e/ou motivação para a realização de determinada tarefa (KOOLE, 2009).

Nos Aspectos Sociais, temos: 1 - Conversação e Cooperação: afeta a qualidade e a quantidade de comunicação, podem ocorrer falhas de comunicação quando nenhuma das 4 máximas (quantidade, qualidade, relação e maneira) não for cumprida; 2 - Interação Social: conversa como atividade cooperativa, compartilhamento 
de sinais e símbolos para contribuir na compreensão das crenças e comportamentos sociais e culturais (KOOLE, 2009).

Após as convergências destes aspectos, Koole (2009) entende que acontece o processo de aprendizagem móvel, proporcionando uma colaboração entre os envolvidos, um acesso à informação de forma adequada e uma contextualização da aprendizagem por parte dos alunos. "[...] a aprendizagem móvel efetiva pode capacitar os alunos, permitindo-lhes avaliar e selecionar informaçóes relevantes, redefinir seus objetivos e reconsiderar sua compreensão de conceitos [...]"2 (KOOLE, 2009, p. 38).

Sendo assim, torna-se necessário observar: a mediação - a natureza da própria interação muda como aprendentes, eles interagem uns com os outros, seus ambientes, ferramentas e informaçóes; o acesso e seleção de informaçóes - à medida que a quantidade de informaçôes disponíveis aumenta, os alunos devem aumentar seus esforços para reconhecer e avaliar a adequação e precisão das informaçôes e a navegação do conhecimento - na produção do conhecimento, os professores determinam o que e como a informação deve ser aprendida. Na navegação do conhecimento, os alunos adquirem habilidades para selecionar, manipular e aplicar informaçóes adequadamente às suas próprias situaçóes e necessidades específicas. Desta forma pode-se desenvolver um ambiente móvel cognitivo (KOOLE, 2009).

\section{Cibercultura e os dispositivos de rede: funçóes e ca- racterísticas dos aplicativos de comunicaçáo do sms ao aplicativo WhatsApp}

Após quase 20 anos de experiência no Yahoo, Jan Koum e Brian Acton, em 2009, lançam o aplicativo WhatsApp, que ini-

2 "[...] effective mobile learning can empower learners by enabling them to better assess and select relevant information, redefine their goals, and reconsider their understanding of concepts [...]" (KOOLE, p. 38, 2009). 
cialmente tinha a função apenas de mostrar o status do usuário, se estava disponível, ocupado, no trabalho, na escola entre outros status. Sim, ele só mostrava o seu status, você entrava e via o status dos amigos. Mas ainda em 2009, resolveram modificar a funcionalidade do aplicativo, tornando possível o envio de mensagens de texto, sendo assim uma alternativa a opção do Short Message Service (SMS). Sendo assim, o WhatsApp é classificado como um aplicativo de mensagem instantânea, esta característica torna a troca de mensagens rápidas, muitas das vezes acontecendo quase em tempo real (WHATSAPP, 2017).

Do seu lançamento em 2009 até os dias atuais, o aplicativo passou por várias modificaçóes e ampliaçóes de seus serviços, muitos deles por solicitação dos usuários. A seguir, com base nas informaçóes disponibilizadas no Blog Whatsapp (2017), blog oficial da empresa, seguem algumas destas evoluçóes. Em 2011, é implementado o grupo no WhatsApp, sendo possível juntar pessoas para compartilhar mensagens em comum e, em 2012, foi disponibilizada a opção de modificar o ícone do grupo e de enviar a localização em que está como forma de mensagem, sendo possível abrir outro aplicativo de mapa para saber onde fica a localidade enviada.

A possibilidade das mensagens de voz é disponibilizada em 2013, sendo apenas necessário clicar no microfone e falar a mensagem. Quem recebe a mensagem de voz, pode notar que antes de ouvir o status do microfone é verde, após ouvir ele modifica para azul e modifica também para quem enviou. Em 2014, o WhatsApp, após sua aquisição pelo Facebook, recebeu investimento para novos desenvolvimentos como poderemos perceber a seguir.

Em 2015, a versão do WhatsApp para o navegador é disponibilizada. Para continuar ativo na versão web, o celular deve estar conectado na internet. As mensagens são replicadas, ou seja, continuam no celular. Também nesse ano disponibiliza a chamada de voz pelo aplicativo, tornando possível substituir a ligação telefônica por uma chamada de voz pelo WhatsApp. 
Durante o ano de 2016, foram disponibilizadas outras funcionalidades, dentre elas: a segurança, com criptografia de ponta a ponta, do envio ao recebimento, deixando as mensagens seguras para os seus usuários. Essa implementação garante o sigilo das mensagens trocadas; a opção de envio de arquivos com até $100 \mathrm{Mb}$; a versão para desktop, ou seja, para baixar e instalar no computador; a possibilidade de editar e melhorar as fotos e vídeos sejam eles produzidos no aplicativo ou que já possua no seu dispositivo e, finalmente, em novembro, foi disponibilizada a opção de chamada de vídeo, por identificar uma necessidade apontada pelos usuários, pois nem sempre os textos, áudios ou vídeos são suficientes para um contato mais profundo, como conversar e ver uma pessoa em tempo real.

Um estudo encomendado pelo WhatsApp ao Analysis Group em 2016, e publicado em 2017, demonstra o impacto que o aplicativo tem na relação dos usuários com empresas, sendo assim, impactando na atividade econômica de uma localidade. Este estudo foi realizado com usuários de países como Brasil, Índia, Alemanha e Espanha, sendo 750 usuários por país, assim distribuídos: 300 em grupos de consumidores e 450 em grupos de pequenas empresas. A pesquisa utilizou grupos focais, pesquisas nacionais representativas e econométricas. Esse estudo serve para demonstrar o real impacto que o WhatsApp possui em nossa sociedade.

A apresentação de dados sobre a internet é muito volátil, pois a velocidade na qual as transformaçóes acontecem mudam em questão de instantes. Antes que termine de ler esta informação os dados já se alteraram, mas se torna necessário expô-los para uma construção de cenário em torno do aplicativo. Em outubro de 2016, o WhatsApp possuía no Brasil mais de 100.000.000 de usuários ativos, o que representava 49\% da população brasileira (205.823.665, estimada em 2016) utilizando o aplicativo (ANALYSIS GROUP, 2017)

Estima-se que foi movimentada com a ajuda do aplicativo, em 2016, uma quantia em torno de 2,9 bilhóes de dólares, apenas no Brasil. Dentre os entrevistados, a maioria (42\%) realiza de 7 a 
9 compras com o uso do WhatsApp semanalmente, ver Tabela 1, o que fortalece a relação do uso do aplicativo no impacto econômico que gera.

Tabela 1 - Quantidade de transaçóes realizadas por meio do WhatsApp em 2016

\begin{tabular}{c|c}
\hline $1-3$ compras & $22 \%$ \\
\hline $4-6$ compras & $24 \%$ \\
\hline $7-9$ compras & $42 \%$ \\
\hline 10 compras & $10 \%$ \\
\hline Não sabe informar & $2 \%$ \\
\hline
\end{tabular}

Fonte: ANALYSIS GROUP. Whatsapp economic impact infographics (2017).

Dentre os concorrentes, a pesquisa identificou que o What$s A p p$ é o mais utilizado no Brasil, quando falamos de aplicativo de mensagens instantâneas. Entre os pesquisados quais os serviços eles mais utilizam: 74,9\% WhatsApp; 61,4\% Facebook Messenger; 22,8\% Skype; 8,2\% Google Hangout, 7,1\% Telegram; 6,8\% iMessage e outros com menos de $5 \%$ cada um.

Tabela 2 - Organizaçóes que mantêm contato via WhatsApp

\begin{tabular}{l|r}
\hline Escolas/Universidades/bibliotecas & $59 \%$ \\
\hline Comunidade / centros de atividades & $21 \%$ \\
\hline Governo/órgão de trânsito & $18 \%$ \\
\hline Centro religioso & $30 \%$ \\
\hline Outros & $9 \%$ \\
\hline Nenhuma das acima & $7 \%$ \\
\hline Não sabe informar & $1 \%$ \\
\hline
\end{tabular}

Fonte: ANALYSIS GROUP. Whatsapp economic impact infographics (2017). 
Quando questionado com quais tipos de organizaçôes eles mantêm contato via WhatsApp, a maioria utiliza para se comunicar com organizaçôes educacionais, como pode-se observar na Tabela 2, desta forma estas instituiçóes já possuem um vínculo com seus alunos relativamente grande, sendo possível direcioná-los para o uso educacional e não apenas para questóes comerciais como demonstrado na pesquisa.

\section{WhatsApp e educação: mapeando os estudos e pesquisas em construçáo no Brasil e em Portugal}

A preocupação aqui não é construir uma análise comparada sobre os dados referentes às duas realidades. Nosso intuito é identificar se e como o aplicativo WhatsApp, como um dos mais utilizados aplicativos digitais de rede de comunicação social já são considerados como objeto de estudos e pesquisas no campo da educação no Brasil e em Portugal, em seguida mapear essa produção e caracterizá-la a partir de sua origem, objetivos, metodologia e resultados. A escolha dos países considera as aproximações históricas das políticas públicas de inserção das Tecnologias digitais de informação e comunicação (TDIC) na educação desses países e aporte de seus autores e as possibilidades de ampliar esse olhar para outra realidade de língua portuguesa.

Para tanto, inicialmente levantamos duas ponderaçóes. Primeiro, em relação a inovação do tema. Apesar de com menos de uma década, consideramos o impacto desse aplicativo nas relaçóes comunicacionais, na telefonia e no processo de socializaçáo no ciberespaço. Cabe aqui retomar Aguado, Feijóo e Martinéz (2013, p. 16), quando observam para os dispositivos móveis "não é só uma nova forma de aproveitar os cenários e ritos de consumo até então. Se trata de um novo meio dotado de um ecossistema próprio, no sentido de atores definidos e relaçóes características entre esses atores". Em seguida, consideramos alguns estudos que atestam a 
resistência de uso dos dispositivos móveis em sala e nos processos de ensino e aprendizagem.

Em Portugal, a integração do uso de tecnologias digitais na educação já ocorre há muitos anos e são impulsionadas por políticas de âmbito nacional nas escolas e universidades do país. Muitos projetos responsáveis por esta integração da TDIC e da internet no ensino escolar e superior foram propostos e implantados pelo $\mathrm{Mi}$ nistério da Educação. São 32 anos de caminhada com políticas que envolveram diferentes tecnologias digitais para uso na educaçáo.

Dentre as políticas estão: Projeto Minerva, ou seja, Meios informáticos no Ensino: Racionalização, Valorização, teve início em 1985 com o objetivo da inserção da Tecnologia de Informação e Comunicação (TIC) nas escolas, entretanto foi lançado em 1996 o projeto Nónio-Século XXI que perdurou até 2002, o próximo Projeto foi o uARTE - Internet na Escolas em 1997 e ficou em vigor até 2003. Em seguida, o Edutic criado pelo Gabinete de Informação e Avaliação do Sistema Educativo (GIASE) que tinha como objetivo dar continuidade ao projeto Nónio - Século XXI. Em 2005 surgiu a equipe de missão Computadores, Redes e Internet da Escola (CRIE) com objetivo de fazer as instalaçóes de computadores e internet nas Escolas.

Até ser elaborada, a maior política de modernização tecnológica do Ministério da Educação elaborada em 2007, denominada "Plano Tecnológico da Educaçáa" (PTE), teve como objetivo colocar Portugal entre os cinco países da Europa com maior modernização tecnológica das escolas até o ano de 2010. Em continuação, criou-se o projeto Internet Segura também em 2007 (ainda em vigor) com o objetivo de conscientizar a sociedade para os riscos associados ao uso da internet. Em 2008 foi implantado o projeto Iniciativa e-Escolinha que pretendeu "assegurar o acesso universal dos alunos do $1^{\circ}$ ciclo do ensino básico e dos respectivos professores a meios informáticos" (Resolução do Conselho de Ministros no 118/2009). 
Neste período, também, foi lançado o projeto do Portátil Magalhães para alunos de seis a onze anos. Em 2010 surgiu o projeto Aprender e Inovar com TIC que teve como objetivo utilizar as TIC para melhorar o aprendizado dos alunos por meio da rentabilização dos aparelhos para as escolas, privilegiando o $1^{\circ} \mathrm{Ciclo} \mathrm{do}$ Ensino Básico português.

Em face às realidades dos projetos não se pode negar o empenho português com as diferentes tentativas de integrar nas suas práticas pedagógicas o uso das tecnologias digitais. Elas possibilitam as novas formas com as quais pesquisamos, organizamos a informação e como passamos a nos comunicar, principalmente no que diz respeito a comunicaçáo entre professor e aluno. Hoje, muitos aplicativos da comunicação utilizados no âmbito social, foram inseridos no processo de aprendizagem, como o WhatsApp.

Especialmente ao tratar do uso desta tecnologia digital da comunicação no processo de aprendizagem, as práticas portuguesas apresentam algumas diferenças das práticas brasileiras e faz-se necessário conhecer os hábitos dos portugueses para chegar a algumas conclusóes. Os portugueses não utilizam com tanta frequência o WhatsApp como os brasileiros e algumas investigaçóes ajudam a justificar esta afirmação.

De acordo com a pesquisa da We Are Social e o Hootsuite a Digital in 2017: Western Europe, estudo que tem como objetivo apresentar resultado sobre o uso da internet, das mídias sociais e o uso dos dispositivos móveis em toda a Europa, o resultado divulgado em janeiro de 2017 afirma que do total de 10,28 milhóes de portugueses, 6,10 milhóes deles são utilizadores das redes sociais, onde 5,20 milhóes utilizam as redes móveis para acessar as redes sociais, sendo que esta rede social é o Facebook, confirmada por $69 \%$ e, consequentemente, informaram que utilizam o chat desta rede social com maior frequência (41\%), a frente do WhatsApp que obteve $27 \%$ das respostas. 
Outros dados que procuram confirmar o uso desta tecnologia digital da comunicação são apresentados na tese de doutoramento realizada na Universidade de Lisboa em 2016. Intitulada "Cyberbullying: a violência virtu@l conectada ao mundo real dos estudantes em contextos universitários do Brasil e Portugal” tem como objetivo "compreender como os estudantes do Brasil e de Portugal percepcionam o clima institucional e psicossocial nas suas universidades e como vivenciaram a problemática do cyberbullying".

Foram entrevistados 642 universitários brasileiros e 770 universitários portugueses. Em face aos resultados, a investigação obteve dados sobre o uso de tecnologias digitais utilizadas pela vitimização nos países. Em relação a Portugal, o resultado esteve sempre atrás do Brasil no que se refere ao uso do WhatsApp. A Tabela 3, a seguir, foi construída a partir dos dados da tese e apresenta números que são fundamentais para a justificativa do uso desta plataforma digital em Portugal.

Tabela 3 - Tecnologias utilizadas na vitimização em Portugal e no Brasil

\begin{tabular}{c|c|c}
\hline Tecnologias & Portugal & Brasil \\
\hline Facebook & $60,2 \%$ & $65,9 \%$ \\
\hline Messenger & $19,3 \%$ & $14,2 \%$ \\
\hline SMS/MMS & $23,6 \%$ & $8,1 \%$ \\
\hline WhatsApp & $1,6 \%$ & $24,8 \%$ \\
\hline
\end{tabular}

Fonte: Produção dos autores.

Os números da Tabela são interessantes e apresentam resultados que nos permitem refletir sobre as tecnologias utilizadas nos dois países. Quanto ao uso do Facebook e do Messenger, os dados se aproximam, mas no que se refere ao uso SMS/MMS há uma grande diferença. No Brasil houve um número pequeno de utilizadores e ao contrário aconteceu com o uso do WhatsApp, onde o número 
foi mínimo entre os portugueses e houve um maior número de aderência dos brasileiros.

$\mathrm{Na}$ Tabela 4, os números referentes ao SMS/MMS em Portugal também tiveram maior aderência em relação ao resultado do Brasil e, mais uma vez, o uso do WhatsApp obteve maior quantitativo do que em Portugal, diferença significativa.

Tabela 4 - Tecnologias utilizadas nas agressóes

\begin{tabular}{c|c|c}
\hline Tecnologias & Portugal & Brasil \\
\hline Facebook & $64,9 \%$ & $53,6 \%$ \\
\hline Messenger & $13,8 \%$ & $20,3 \%$ \\
\hline SMS/MMS & $17,0 \%$ & $5,8 \%$ \\
\hline WhatsApp & $6,4 \%$ & $41,3 \%$ \\
\hline
\end{tabular}

Fonte: Produção dos autores.

Apesar de ser uma investigação específica na área da Psicologia, os dados auxiliam para a discussão do uso das tecnologias digitais da comunicação nos dois países. $\mathrm{O}$ resultado também é interessante pelo fato de apresentar a frequência de uso do SMS/MMS.

Outro estudo realizado na Universidade de Aveiro (Portugal) por Santos (2012), intitulado "SMS: uma nova forma de comunicação, uma influência na Língua Portuguesa”, apresenta dados que comprovam a evoluçáo do SMS e importância que o SMS tem em Portugal sobrepondo as novas tecnologias digitais da comunicação.

Vinte anos após o início da implementação das SMS como forma de comunicação escrita, estas já não precisam de mostrar o seu valor nem de dar provas da sua utilidade. Hoje debatem-se com uma concorrência nova, diferente e recente, que são as redes sociais e os serviços de mensagens instantâneas agora existentes no telemóvel como o 
Viber $^{\oplus}$ e o Whatsapp (uma aplicação de SMS para Smartphones) que elevam a qualidade das SMS, possibilitando enviar mensagens de texto gratuitas para outros destinatários desde que os destinatários também tenham instalada a mesma aplicação, independentemente do tarifário em vigor. (SANTOS, 2012, p. 15).

$\mathrm{O}$ autor ainda afirma que o SMS tem muitas vantagens, além de ser mais confidencial esta forma de comunicação não necessita da utilização da rede de internet e o tarifário é muito mais em conta devido às promoçóes que são lançadas pelas operadoras de telecomunicaçôes móveis e devido aos tarifários pré-pagos.

Em contraponto, dados mais atuais vêm demonstrar que o uso de mensagens instantâneas por meio da internet está sendo uma prática adotada pelos portugueses e em expansão.

De acordo com o relatório estatístico dos serviços móveis referente ao $3^{\circ}$ trimestre de 2016, houve um decréscimo do envio de SMS para um acréscimo de mensagens por meio das tecnologias digitais pelo telefone celular, o que é compreensível devido a proporção em que as tecnologias digitais estão inseridas no cotidiano das pessoas.

Cerca quatro em cada cinco utilizadores do serviço de acesso à Internet através do telemóvel envia mensagens instantâneas (instant messaging). Esta redução é visível sobretudo nos escalóes entre os 15 e os 34 anos, que são aqueles onde se verifica uma utilizaçáo mais intensiva deste serviço. Os utilizadores de SMS nestes escalóes diminuíram cerca de 3 p.p. nos últimos dois anos, tendo simultaneamente aumentado a utilização de serviços de instant messaging em cerca de 40 pontos percentuais. (ANACOM, 2016, p. 19-20). 
O que não se pode afirmar especificamente é quais são as plataformas utilizadas nas mensagens instantâneas, mas os exemplos citados na investigação destacam o Facebook, Messenger e WhatsA$p p$. O que pode nos ajudar a pensar sobre qual plataforma é mais utilizada pelos portugueses e principalmente no que se refere ao uso educacional são os trabalhos acadêmicos, as dissertaçóes e as teses.

Para revisitar os trabalhos realizados em Portugal, procuramos mapear por meio do Repositório Científico de Acesso Aberto de Portugal (RCAAP), vinculado às universidades portuguesas, não houve resultado de dissertaçóes ou teses portuguesas sobre as experiências no uso do WhatsApp na educação. Ao realizar a pesquisa com o termo WhatsApp referente ao título, resumo ou palavra-chave os resultados obtidos apresentaram dissertaçôes e teses vinculadas a instituições brasileiras.

No Brasil, também as políticas de inserção de TDIC na educação remontam a década de 1980 com projetos que tinham como objetivo inserir as tecnologias digitais no ensino. $\mathrm{O}$ primeiro projeto chamava-se Projeto Educação com Computadores (EDUCOM) foi em 1983 e o projeto realizou a implantação de centros-pilotos em universidades públicas direcionados a pesquisa no uso de informática educacional para elaboração de softwares educativos, além da educação especial.

Seis anos depois surge o Programa Nacional de Informática Educativa (PRONINFE) que buscava apoiar o desenvolvimento e a utilização da informática nos ensinos do $1^{\circ}, 2^{\circ}$ e $3^{\circ}$ graus e educação especial, estimulava a criação de vários centros distribuídos pelo país, trazia a capacitaçáo contínua e permanente de professores para que fosse possível uma fundamentação pedagógica eficaz no uso das tecnologias. Outro projeto foi iniciado em 1992 e tinha a televisão como a tecnologia fundamental, foi o projeto Salto para o Futuro que tinha como ideal aperfeiçoar os professores da rede pública de ensino e dar formação continuada aos professores responsáveis pelo ensino fundamental e médio, todos da rede pública de ensino. 
Atualmente este projeto é um programa de TV passado nacionalmente que tem intuito de abordar diversas temáticas educacionais.

Em 1995, ainda com foco na televisão e também em VHS e DVD, é criado o projeto TV Escola que foi a primeira medida após o Decreto no 1.917/96 que criou as Secretarias Estaduais de Educação a Distância (SEED). Este projeto teve como objetivo capacitar professores do ensino fundamental e médio para o uso das ferramentas distribuídas pelo projeto com o intuito de contribuir com o aprendizado dos alunos. As ferramentas faziam parte do chamado Kit tecnológico uma antena parabólica, uma TV de 20 polegadas, um videocassete e 10 fitas VHS virgens, depois houve uma reformulação para DVD.

Também na busca de melhorar a qualidade do ensino foi criado o Programa Nacional de Informática (PROINFO), em 1997, que tinha como objetivo a formação inicial de 25 mil docentes na tentativa além da capacitação de técnicos de informática para a manutenção das ferramentas. O Programa Mídias na Educação foi lançado em 2005, era um programa de educação a distância, com estrutura modular, que visa proporcionar formação continuada para o uso pedagógico das diferentes tecnologias da informação e da comunicaçáo e tinha como principal público os professores da educação básica.

Em 2010, foi implementado nas escolas públicas um projeto semelhante ao projeto Portátil Magalhães em Portugal, Programa Um Computador por aluno (PROUCA). Foi entregue a cada aluno, por meio do Ministério da Educação, um laptop onde encontram-se programas educativos, games, fotos e comunicador instantâneo para auxiliar na aprendizagem, mais uma tentativa de inclusão digital na escola. Em atualização no ano de 2012 o projeto foi reformulado para uso de tablets, conhecido como Tablets na educação.

Quanto aos estudos sobre WhatsApp no Brasil, procuramos organizar os dados em dois momentos. No primeiro, Quadro 1, 
apresentamos um diagnóstico das linhas de pesquisa e sua localização territorial desses estudos, incluindo o ano de apresentação dos resultados. Num segundo momento, destacamos como o Whats $A$ $p p$ foi utilizado nas pesquisas, os objetivos, metodologias e resultados desses estudos.

Quadro 1 - Diagnóstico da distribuição territorial e institucional dos estudos

\begin{tabular}{|c|c|c|}
\hline Ano & Área & UE \\
\hline 2015 & LINGUAGENS E LETRAMENTOS & $\mathrm{PE}$ \\
\hline 2015 & LINGUAGENS E LETRAMENTOS & RGN \\
\hline 2015 & EDUCAÇÃO MATEMÁTICA & MGS \\
\hline 2015 & DIVERSIDADE E INCLUSÃO & RJ \\
\hline 2015 & ESTUDOS CULTURAIS & SP \\
\hline 2015 & EDUCAÇÃO BRASILEIRA & $\mathrm{CE}$ \\
\hline 2015 & EDUCAÇÃO E CONTEMPORANEIDADE & BA \\
\hline 2015 & ENSINO DE FÍSICA & $\mathrm{RJ}$ \\
\hline 2015 & LINGUAGENS E LETRAMENTOS & RGN \\
\hline 2015 & $\begin{array}{c}\text { DESENVOLVIMENTO SUSTENTÁVEL E } \\
\text { TRABALHO }\end{array}$ & RJ \\
\hline 2015 & CULTURA E SOCIEDADE & MA \\
\hline 2015 & LINGUAGENS E LETRAMENTOS & SC \\
\hline 2016 & ENSINO DE MATEMÁTICA & PR \\
\hline 2016 & ENSINO DE HISTÓRIA & TO \\
\hline 2016 & FILOSOFIA E ENSINO DE FILOSOFIA & RJ \\
\hline 2016 & $\begin{array}{c}\text { TEORIA E ANÁLISE DA ORGANIZAÇÃO } \\
\text { LINGUÍSTICA }\end{array}$ & PE \\
\hline 2016 & ENSINO DE ARTES & MG \\
\hline
\end{tabular}




\begin{tabular}{|c|c|c|}
\hline Ano & Área & UE \\
\hline 2016 & DISCURSOS MIDIÁTICOS E PRÁTICAS SOCIAIS & RJ \\
\hline 2016 & ENSINO DE CIÊNCIAS E MATEMÁTICA & MG \\
\hline 2016 & MATEMÁTICA & RJ \\
\hline 2016 & $\begin{array}{c}\text { EDUCAÇÃO BRASILEIRA: GESTÃO E PRÁTICAS } \\
\text { PEDAGÓGICAS }\end{array}$ & MG \\
\hline 2016 & ENSINO, CIÊNCIAS E NOVAS TECNOLOGIAS & PR \\
\hline 2016 & SAÚDE BUCAL & $\mathrm{DF}$ \\
\hline 2016 & LINGUÍSTICA & $\mathrm{AL}$ \\
\hline 2016 & ENSINO, CIÊNCIAS E NOVAS TECNOLOGIAS & PR \\
\hline 2016 & ARTES & MA \\
\hline 2016 & EDUCAÇÃO & SE \\
\hline 2016 & EDUCAÇÃO & $\mathrm{DF}$ \\
\hline 2016 & $\begin{array}{c}\text { GESTÃO DE SISTEMAS DE INFORMAÇÃO E DE } \\
\text { CONHECIMENTO }\end{array}$ & $\mathrm{BH}$ \\
\hline 2016 & EDUCAÇÃO E CONTEMPORANEIDADE & $\mathrm{BA}$ \\
\hline 2016 & LINGUAGENS E LETRAMENTOS & $\mathrm{BA}$ \\
\hline
\end{tabular}

Fonte: pesquisa dos autores.

Do total das 30 dissertaçóes pesquisadas, 12 foram defendidas em 2015 e 18 em 2016, destas, 4 são de mestrados profissionais, nas linhas de arte, matemática, gestão e somente uma se aproxima mais do campo da educação, na linha de ensino de ciências. Quanto às áreas, a proposta foi delimitar a Educação e a Comunicação e Informação como marcos centrais e áreas base e mapear o entorno, as aproximaçóes e roteiros por outras áreas. Neste sentido, merece destaque oito dissertaçóes em linhas que têm a Educação como fundamento (duas em Educação, duas em Educação Brasileira, duas em Educação e Contemporaneidade, além de uma em trabalho em discursos midiáticos e uma em estudos culturais). 
Na relação ensino e educação, podemos destacar nove dissertações (duas em Ensino, Ciências e Novas Tecnologias, duas em Ensino de Matemática e uma em Ensino de Ciências e Matemática, uma para o ensino de Física, Artes, História e Filosofia). Abrimos um parêntese para identificar o campo da Linguística, Letras e Artes com seis trabalhos, seguidos pela Matemática com quatro dissertaçóes.

Sobre a forma de utilização do WhatsApp nesses estudos, podemos destacar pelo menos duas. Uma direta e outra indireta. $\mathrm{Na}$ primeira, a ferramenta faz parte da própria pesquisa como estratégias e pedagogia fundamental, utilizada nas intervençóes ou pesquisa ação. Os pesquisadores utilizaram essa ferramenta para criar grupos que subsidiam as pesquisas, as práticas pedagógicas propostas, para compartilhar imagens e textos, tirar dúvidas, apresentar documentos para ampliar os conteúdos trabalhados em sala, sugerir leituras complementares e fortalecer o contato e a interação entre alunos e destes com os professores. Num outro grupo estáo os pesquisadores que usaram a ferramenta como instrumento de pesquisa, a partir dos grupos já criados foram usados como instrumento de pesquisas por meio do monitoramento das conversas e discussóes registrados nesses espaços.

A perspectiva de destaque do WhatsApp como objeto de pesquisa está clara quando analisamos os objetivos. Somente dois trabalhos, que corresponde a $6 \%$ do total pesquisado, trazem indiretamente essa ferramenta como objeto relacionado às TIC e as redes sociais. No restante dos outros, a ferramenta aparece nos específicos. Mais de $70 \%$ das pesquisas ocorreram na educação básica, com destaque para o ensino médio, no campo da linguagem, envolvendo o ensino de Português, Espanhol e Inglês. A educação a distância parece com experiências na Odontologia, na Filosofia, História e na formação continuada de professores. Outras áreas de formação superior foram contempladas com experiências no campo das Artes, da Matemática com cálculo diferencial e estágio não obrigatório. 
No tocante aos resultados das teses e dissertaçóes serve, para a maioria, as observaçóes de Lira (2015, p. 4) quando afirma que,

pedagogicamente, o uso da plataforma WA possibilita, em momentos extraclasse, o envio de comentários, questionamentos, avisos, a resolução de exercícios em grupos, enfim, a criação de uma espécie de intercâmbio progressivo de informação e conhecimento. Possibilita contatos interativos possibilita ainda o intercâmbio de leituras, trocas de interpretaçóes e o encaminhamento para leituras.

Para além dessa generalização, destaca-se também o uso da ferramenta como espaço de diálogo, para manter os estudantes envolvidos. Para os professores, nas experiências de intervenção, pesquisa ação e ou participantes, a plataforma contribui positivamente para a prática docente e amplia o espaço da sala de aula para além de seus muros. A cooperaçáo interativa aos ambientes virtuais e aprendizagem, as práticas de educação on-line e como instrumentos de pesquisa como espaço de registro de falas e texto, além de espaços de diálogo e discussão que podem ser usados como grupos focais.

Em seu estudo, Cavalcante (2016, p. 18) chama atenção para as características metalinguísticas da ferramenta. Para o autor ,o WhatsApp possibilita o "uso intenso de intersemioses áudio-escrita-imagens-emoticons, que configuram em um mosaico de semioses multimodais, que se (re)significam num mesmo espaço". No entanto, levanta também algumas questóes sobre o acesso a informaçóes referentes a pornografia, a exigência de uma dedicaçáo permanente por parte dos professores para responder e atender aos alunos.

\section{Conclusóes}

Podemos concluir que estamos diante de um paradoxo. Conhecemos as transformaçóes comunicacionais e sociais que a fer- 
ramenta WhatsApp vem provocando, desde seu lançamento aos dispositivos móveis e a telefonia digital, mas estamos diante de um novo objeto, notado, mas ainda não muito estudado por pesquisadores da educação. No entanto, já é perceptível o crescimento do interesse nesta ferramenta como centro ou periferia nas discussóes a respeito do impacto dos dispositivos móveis, das redes sociais digitais, dessa ferramenta multilinguística e multimidiática de comunicação, dos novos ambientes e plataformas de educação.

Em se tratando do WhatsApp mais especificamente, ainda náo nos parece ser uma preocupação de pesquisa para os portugueses. $\mathrm{O}$ número de trabalhos localizados para esta pesquisa ainda é muito pequeno. No entanto, em relação ao Brasil, conseguimos identificar 34 trabalhos no período de dois anos (2015/2016). Em várias áreas de conhecimento, com destaque para a educação e o campo da linguística. Teses (4) e dissertações, acadêmicas e profissionais esses trabalhos estão voltados para intervenção e pesquisa ação na prática docente e nos processos de aprendizagem com mediação das Tecnologias Digitais de Informação e Comunicação, com especial atenção para as redes sociais digitais - o WhatsApp e o Facebook.

Podemos concluir, considerando a pouca produção portuguesa, que a ferramenta e seu consumo no cotidiano social como meio de comunicação, acesso e troca de informação tem se ampliando e interferido no espaço escolar de forma positiva e negativa. Assim, como as pesquisas no Brasil chamam atenção para o fato da escola e dos docentes tentarem entender o fenômeno e sua influência na vida dos alunos e o impacto na aprendizagem. Se podem e como podem contribuir para melhorar a atenção, a interação, a colaboração, os interesses e a melhoria da aprendizagem com jovens e adolescentes. 


\section{Referências}

AGUADO, Juan Miguel; FEIJÓO, Claudio; MARTINÉZ, Inmaculada J. Introdución: de la cuarta pantallamal medio líquido. In: AGUADO, Juan Miguel; FEIJÓO, Claudio e MARTINÉZ, Inmaculada J. La comunicación móvil: hacia un nuevo ecosistema digital. Barcelona: Gedisa, 2013.

ANACOM. Serviços móveis: informação estatística $3^{\circ}$ trimestre de 2016. Disponível em: <https:/www.anacom.pt/streaming/ STM3T16.pdf? contentId=1400752\&field=ATTACHED_FILE $>$. Acesso em: 12 jun. 2017.

\section{ANALYSIS GROUP. Whatsapp economic impact} infographics. 2017. Disponível em: <http://www.analysisgroup. com/uploadedfiles/content/ news_and_events/news/ analysisgroup_whatsapp_economic_impact_report.pdf $>$. Acesso em: 10 jun. 2017.

CAVALCANTE, F.L. O trabalho com a oralidade: proposição, aplicação e análise de um debate regrado via whatsapp. 2016. Dissertação (Mestrado) - Universidade Católica de Pernambuco, Recife, 2016.

DEWEY, J. Democracia e educação. São Paulo: Companhia Editora Nacional, 1936.

KOOLE, M.L. A Model for Framing Mobile Learning. In: Mobile Learning: Transforming the Delivery of Education and Training, Edmonton. AU Press, 2009. Disponível em: <http://www.aupress.ca/books/120155/ebook/99Z_Mohamed_ Ally_2009-MobileLearning.pdf>. Acesso em: 10 jun. 2017. 


\section{LIRA, V.L. de S. Smartphone e ensino de língua portuguesa:}

lidando com conjuntos e sistemas de gêneros em atividades no whatsapp. 2015. Dissertação (Mestrado profissional em Letras) - Programa de Pós-Graduação em Letras - PROFLETRAS, Universidade de Pernambuco, Garanhuns, 2015.

OKADA, Alexandra. O que é cartografia cognitiva e por que mapear redes de conhecimento? In: Okada, Alexandra (Ed.). Cartografia Cognitiva: Mapas do conhecimento para pesquisa, aprendizagem e formação docente. Porto Cuiabá, Mato Grosso: KCM, 2008.

OXFORD DICTIONARIES. Blog Oxford Dictionaries. 2015. <http://blog.oxforddictionaries.com/2015/11/word-of-the-year2015-emoji/>. Acesso em: 10 jun. 2017.

SANTOS, A.M.A. de A. SMS: uma nova forma de comunicação, uma influência na Língua Portuguesa. 2012. Dissertação (Mestrado) - Universidade de Aveiro, Portugal, 2012.

SHARPLES, M.; TAYLOR, J.; VAVOULA, G. A Theory of Learning for the Mobile Age. In: The Sage Handbook of E-learning Research, London: Sage, 2007. p.221-247. Disponível em: < https://telearn.archives-ouvertes.fr/file/index/ docid/190276/filename/Sharples_et_al_Theory_of_Mobile_ Learning_preprint.pdf>. Acesso em: 10 jun. 2017.

SOUZA, S.B. de. Cyberbullying: a violência virtu@l conectada ao mundo real dos estudantes em contextos universitários do Brasil e Portugal. 2016. Tese (Doutorado) - Universidade de Psicologia, Universidade de Lisboa, Portugal, 2016.

TRAXLER, J. Current State of Mobile Learning. In: TRAXLER, J. Mobile learning: Transforming the Delivery of Education and 
Training, Edmonton. AU Press, 2009 p.9-24. Disponível em: <http://www.aupress.ca/books/120155/ebook/99Z_Mohamed_ Ally_2009-MobileLearning.pdf>. Acesso em 10 jun. 2017.

WE Are Social e o Hootsuite a Digital in 2017: Western Europe. Disponível em: <https://wearesocial.com/special-reports/digitalin-2017-global-overview>. Acesso em: 10 jun. 2017.

WHATSAPP. Blog do Whatsapp. 2017. Disponível em: <https:// blog.whatsapp.com/>. Acesso em: 10 jun. 2017. 